In the treatment of both these cases great care was taken to make it as much "open air" as the means at our command permitted. The elder patient had the advantage in this respect, as, being a private case, the windows could be opened without regard to anybody's welfare but her own, and she has also been able to make prolonged stays at the seaside. She has regained more vigorous health than the younger. Still the latter has done well and benefited by a stay at the Yarrow Home, Broadstairs. It is interesting to add that through the generosity and gratitude of friends of the younger patient the hospital in which she was treated has profited to the extent of $£ 575$, which illustrates what I should venture to state as an established fact that our hospitals are supported by their beds-i.e., by the work done in them. It is a pity that committees and secretaries are prone to be disposed to fritter away the earnings of the beds on bloated and abused out-patient departments.

$A$ case of tubercle of the appendix and of the meso-cacal glands. - The patient, aged 11 years, was admitted into West London Hospital on July 16th, 1901. On July 7th she had cowplained of great pain in the right groin which was very acute at times and had been more or less severe since. She had been subject to similar attacks off and on for the last two years. She had had measles and whooping-cough but not scarlet fever. The bowels were opened freely after a simple enema. The patient appeared to be a healthy, wellfed child with no marked abnormality of any kind. When asked to point out the seat of pain she placed her hand on the abdomen below, and a little to the right of, the umbilicus. The lungs and the heart appeared bealthy and the resonance note of the abdomen was quite normal. On palpating a certain abnormal feeling of resistance could be felt over the region of the cæcum

On July 19th an incision of about three inches was made along the right linea semilunaris, The cæcum was drawn out and the appendix was found to be bound down tightly to the gut by tuberculous adhesions. The appendix was excised and the stump was invaginated and stitched. A large tumour lying behind the peritoneal attachment of the cæcum was next cut into and a mass of curdy pus was evacuated. The cavity was then scraped and iodoform gauze packing was inserted. The cavity was then approximated to the operation opening and fastened by a few sutures to its edges. The gauze packing projected outside and the wound was partially closed. A few smaller glands in the mesentery were left untouched. On the 20th the wound was dressed and the iodoform packing was removed and fresh packing inserted. On the 22nd the wound was again dressed and fresh packing was inserted. There was slight pain at intervals. On the 23rd the bowels were moved slightly and there was some pain. On the 24th the patient was very restless. She complained of pain in the lower bowel. Rectal examination showed masses of scybala. A simple enema gave relief. The wound was again dressed on the 25th. The patient had had a comfortable day and she slept at night. She was discharged from hospital on August 22nd, the wound having quite healed (34 days after the operation). The temperature, $100^{\circ} \mathrm{F}$. on admission, never once rose above $99^{\circ}$ after the operation.

Now, with regard to tuberculosis confined to the peritoneal coat of the cæcum and appendix. By chance I operated on a case of this description only yesterday (May 13th). A tall, well-made, and well-developed young woman, aged 19 years, is described as having been the picture of health till a year ago, when she began to be worried with recurrent abdominal pains, rather vague in situation but more in the right side than the left. Once appendicitis was diagnosed. Vague as they were these pains and illnesses were described as making life scarcely worth living. What was thought to be the appendix and ileo-cæcal valve could be felt by palpation and was tender. Her only brother had had appendicectomy performed. Her bowels were irregular, generally constipated. At the operation the incision was made over the appendix but $I$ first through this incision palpated the gall-bladder. The appendix and the ovary felt normal though the former, as in her brother's case. was rather long. The cæcum was now pulled out. I examined the appendix, cæcum, meso-cæcum, and part of the ascending colon very carefully for abnormalities and especially for tubercles but noticing only one solitary suspicious and very minute nodule was going to give up the search when, turning the cæcum over, Dr. H. J. Davis, who was present, observed a colony of tubercles confined to the under or right side of that viscus. One tubercle only was discoverable on the appendix itself near its base. The omentum and a coil of small intestine with its mesentery were now searched for tubercle with a negative result. The parietal peritoneum appeared quite free and no glands could be felt. The wall of the cæcum was perhaps a little thick. I removed the appendix, which when slit up showed a rather granular catarrhal condition of the mucous membrane. It had contained a small fæcal concretion which I had slipped on into the cæcum while manipulating it. I did not feel called upon to remove this crcum. The disease is in an exceedingly early stage, the patient is personally vigorous, and she is in a position to live an outdoor life and to stay at the seaside or in the country as long as may be desired. And it will be granted that serious operations for local manifestations of what may be a more generalised condition should be resorted to with discretion.

Those who wish to make acquaintance with anatomical and histological details of tuberculosis of the cæcum and appendix will find them fully and lucidly given, with admirable illustrations, in Dr. Howard Kelly's great work on the appendix.

A conviction which I published some years ago and have often expressed is that general tuberculous peritonitis often arises in tubercle of the crecum or in the mesu-cæcal glands, that whenever laparotomy is performed for that disease the cæcum, meso-cæcum, and appendix should if possible be examined, and, at least in males, the question should be entertained of incising in the right iliac region rather than in the median line. In females, of course, there is always the possibility of the primary focus being in the left uterine appendage. These views were brought forcibly home to me by a case in which I excised a small tumour from the cæcal region. It lay near the junction of the mesocæcum with the ascending meso-colon and proved to be a bag of cheesy pus, so thin-walled that the slightest blow would have extravasated its contents into the peritoneal cavity, and the same views are supported by the cases just related. Further, these cases show that in dealing with this singular disease it is not too late to lock the stable door even when the horse is apparently stolen.

Lastly, I would point out that there might be a fair hope of curing ileo-cæcal and appendical tuberculosis without excising the disease, and merely by an ileostomy combined with suitable general treatment. I infer this from the good $r \in$ sults I have seen ensue from treating extensive tuberculous ulceration of the rectum with fistulæ, by simple scraping combined with an inguinal colotemy kept open until the tuberculous ulceration had thoroughly healed. But I think excision preferable. Whether an ileo-sigmoidostomy would prove curative or not is doubtful. After that operation fæcal matter is not long before it finds its way back along the colon to the croum.

\section{A MEANS OF CHECKING THE SPREAD OF "SLEEPING SICKNESS."}

BY JOHN L. TODD, B.A., M.D., C.M. McGILL, DIRECTOR OF THE RUNCORN RESEARCH LABORATORIES OF THE LIVERPOOL SCHOOL OF TROPICAL MEDICINE.

THIS paper has been drafted to indicate to those who have not followed the subject closely the wide distribution of human trypanosomiasis in Africa, to demonstrate the rapidity with which the disease is spreading, and to suggest measures intended to check further extensions.

Map 1 represents the distribution of sleeping sickness as known at present. The parasite causing the disease, the Trypanosoma gambiense, is ordinarily transmitted from infected to healthy persons by the bite of a tsetse fly, Glossina palpalis. We must therefore expect human trypanosomiasis to spread to the limits of the distribution of this fly. The northern and southern limits of the area in which Glossina palpalis has been found are indicated by dotted lines. 1ts actual distribation will certainly be found to be much wider. There are seven other varieties of tsetse flies and, until the contrary is proved, we must consider the

1 For particulars of the observations and arguments on which thi paper is based see Memoir XVIII., Liverpool School of Tropical Medicine, and the fortheoming volume of the Transactions of the Epidemiological Society, from which Maps 2 and 3 and many of the facts are taken. 
possibility of each of them being also a carrier of the / became easier and more rapid. Expeditions were sent in infection. The part of Africa within which tsetse flies are found is roughly limited by an uninterrapted line. In any case it is evident from an inspection of Map 1 that the uninfected areas of the Soudan, Northern Nigeria, German East Africa, British Central Africa, \&c., are in the greatest danger of being infected.

The history of the various epidemics of human trypanosomiasis shows that it spreads but comparatively slowly from an infected area but that it may easily be oarried, by the advent of an infected person, into localities where it did not various directions to open up the country and military operations were commenced against the Arabs. These large undertakings involved an unprecedented movement of men. Natives-soldiers, workpeople, and their wives-were brought from infected districts to places previously free from the disease. In 1897, 12 years after the foundation of the Free State, cases of sleeping sickness were reported among the natives about Luluabourg and Lusambo (Map 2), places uninfected in 1884 . The caravan routes between Lusambo and Kasongo were formerly much used. It was along

MAP 1.

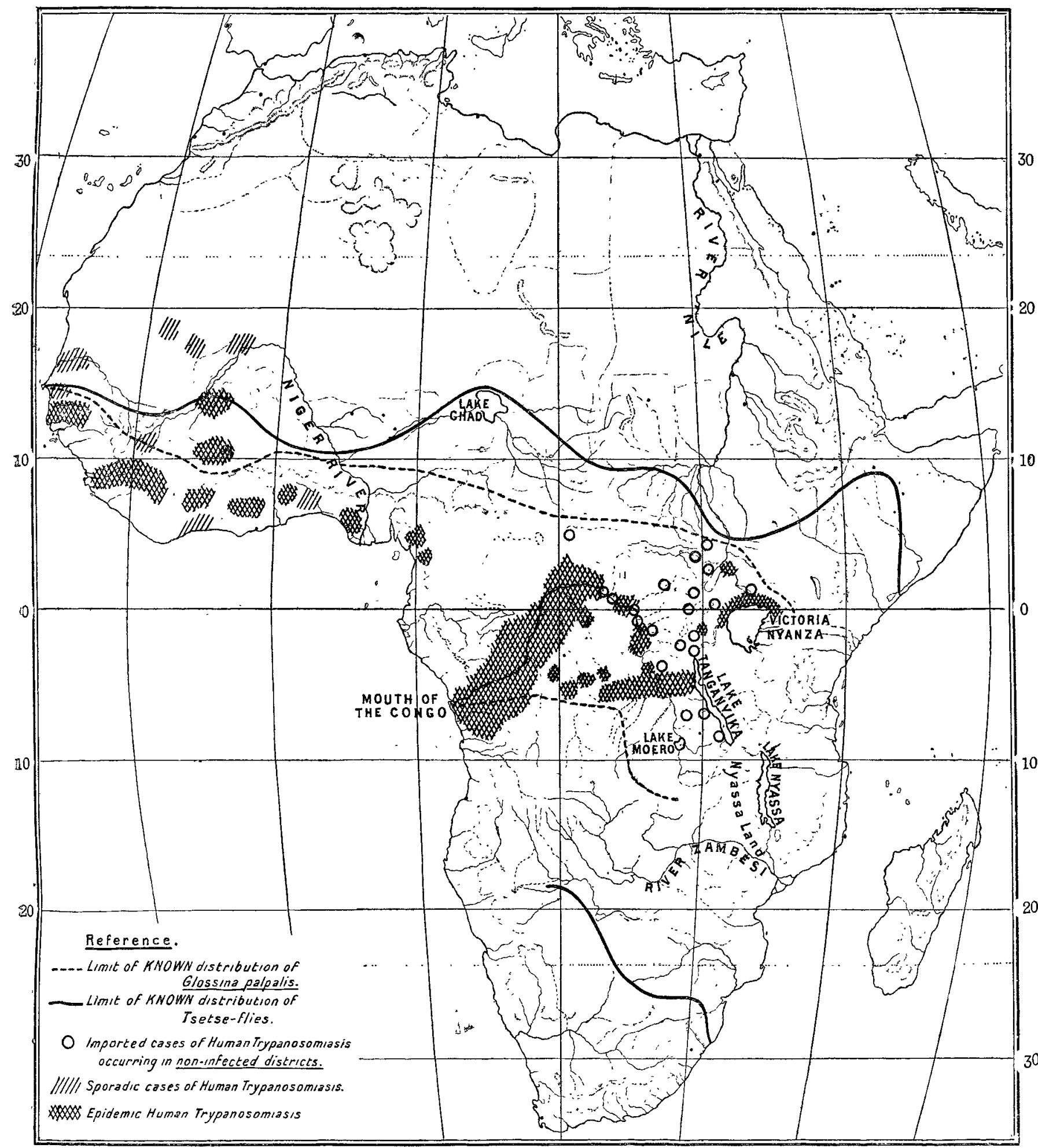

Known distribution of human trypanosomiasis and tsetse flies in Africa, 1905. Compiled from :-1. Laveran and Mesnil: Les Trypanosomes et les Trypanosomiases, 1904. 2. Report No. VI. of the Sleeping Sickness Commission of the Royal Society.

3. Memoir XVIII. of the Liverpool School of Tropical Medicine.

previously exist. In the Congo Free State it is, for example, along the main routes of communication that the disease has spread. Two maps representing respectively the distribution of the disease in the Congo basin in 1897 and 1905 are annexed to demonstrate this point. Before Europeans entered the Congo basin sleeping sickness seems to have been confined to the region of the Lower Congo and to the banks of the main river as far up as Bumba (1884). No record can be obtained of its existence elsewhere. With the coming of the white men steamers were introduced on the rivers, caravan roads were opened up, and long distance transport these routes that the troops directed against the Arabs advanced. Caravans carrying supplies to the posts in the eastern part of the Free State passed over the same roads which were also used by native ond Arab traders. From Kasongo to Baraka and Albertville on Lake Tanganyika go very important caravan routes over which pass the whole of the supplies to the region about Lake Kivu and Lake Tanganyika north of $5^{\circ} \mathrm{S}$. In 1896 the caravan route between Lusambo and Kasongo was closed and the transport between the east and west of the Free State went instead up the Congo in steamers to Stanleyville and thence 
MaP 2.

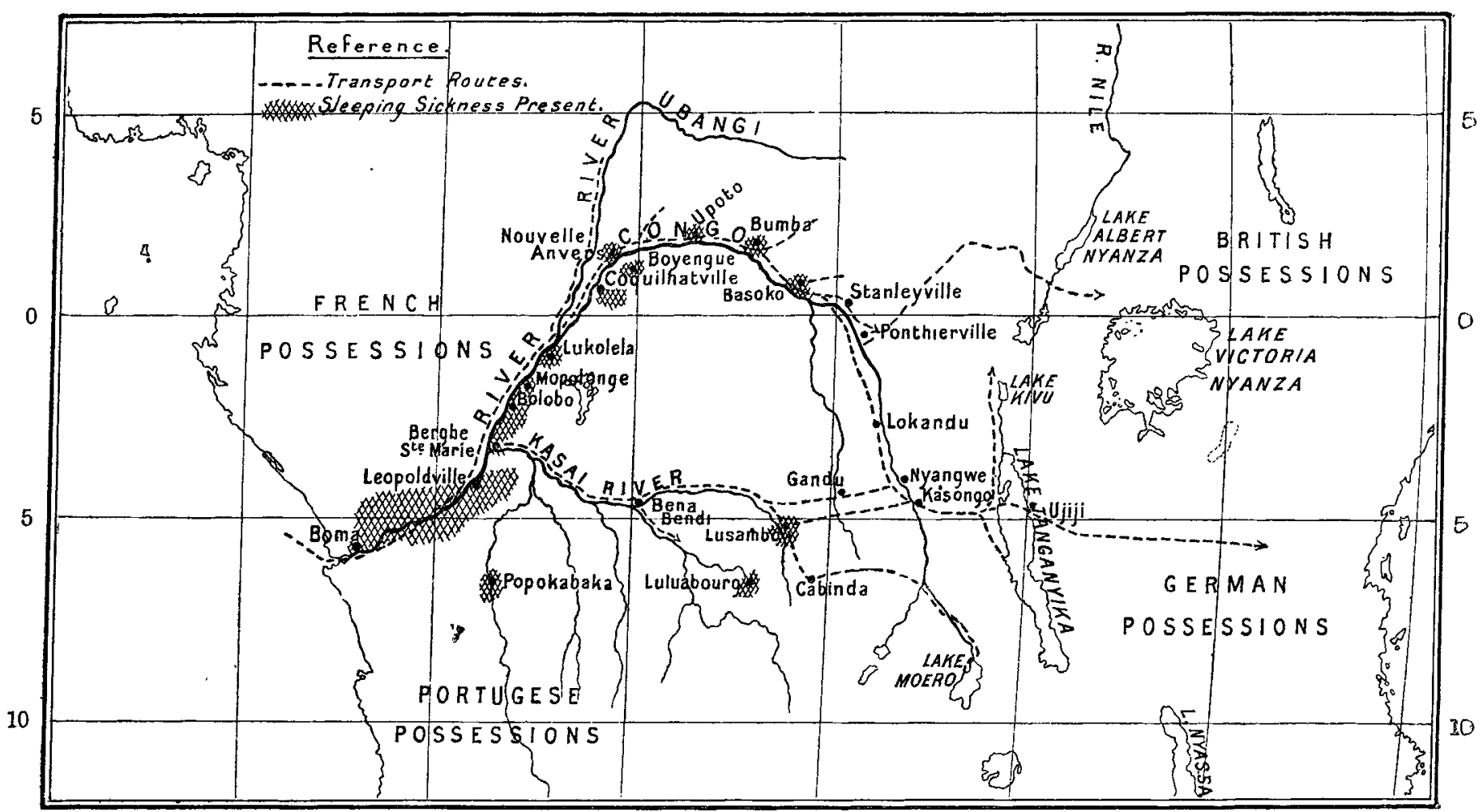

Distribution of "sleeping sickness" in the Congo Free State, 1897.

MAP 3.

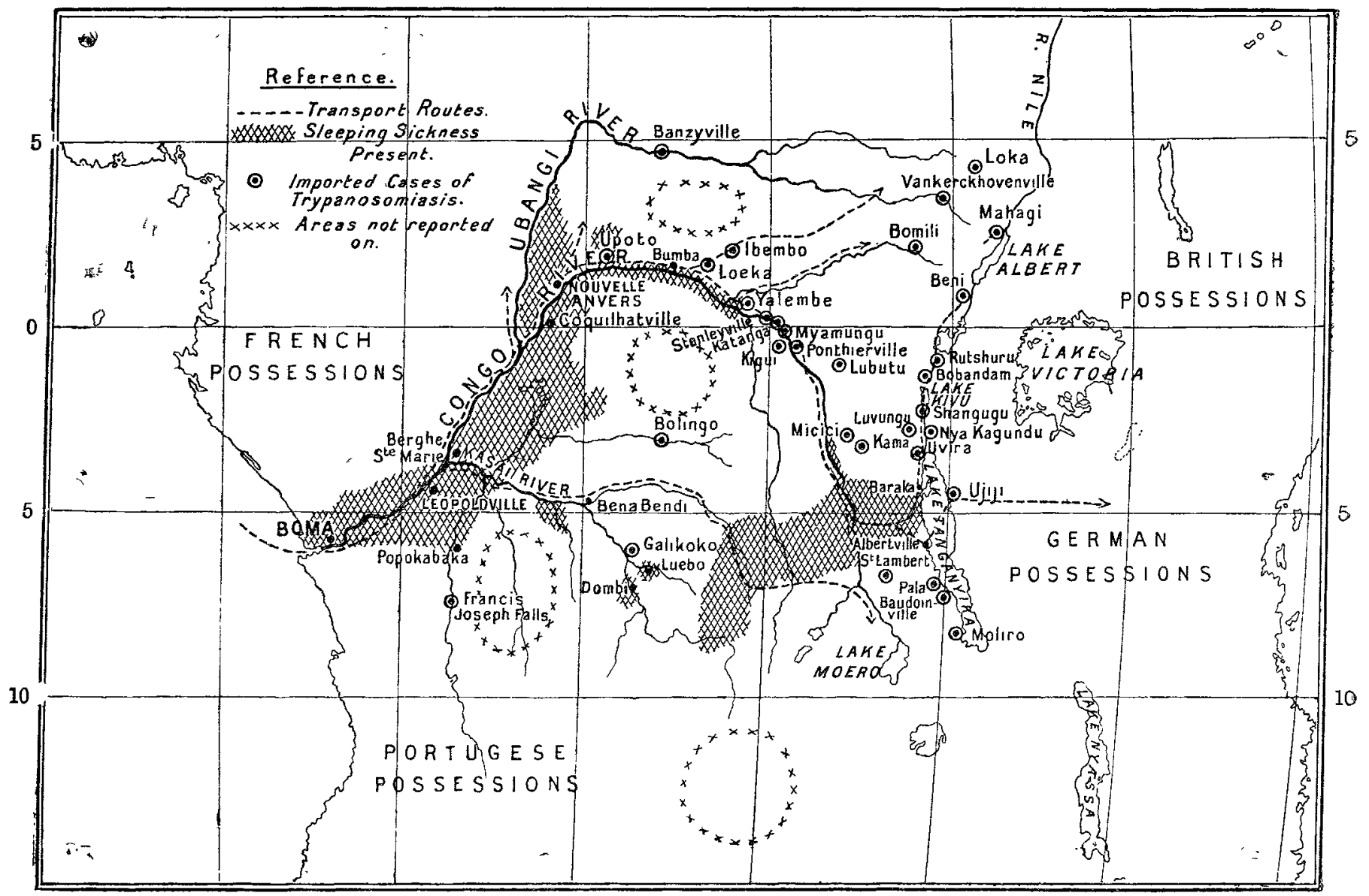

Distribution of "sleeping sickness" in the Congo Free State, 1905. 
by canoes to Kasongo. Map 3 plainly shows the results of these movements. Sleeping sickness has spread along the most important overland routes and up and down the Congo from Kasongo until there are only comparatively small stretches of river between Stanleyville and Kasongo still uninfected. Posts in uninfected districts at which imported cases of sleeping sickness have been reported are indicated by circles. They give some idea of the frequency with which "clean" districts are exposed to infection. All these imported cases are soldiers, labourers, or their wives brought Jong distances from their homes as a direct result of the opening up of the country by Arabs and Europeans. It is evident that if such persons were removed from uninfected districts and if the ingress of others were prevented much would have been done to check the spread of human trypanosomiasis.

It is well known that negroes in the first stages of human trypanosomiasis are often apparently well, make no complaints, and work as effectively as any healthy individual. A means of detecting such cases has recently been devised. Enlarged lymphatic glands had long been observed to occur in cases of trypanosomiasis. Greig and Grey showed that trypanosomes could easily be found in the juice aspirated from such glands by means of a hypodermic syringe. By using this method we found in the Congo that in practice every negro whose neck glands are enlarged without obvious cause must be considered to be a case of trypanosomiasis until the contrary is proved. (This statement is based upon the examination of 6358 apparently healthy negroes of all ages and both sexes.) It is therefore proposed that good results may be expected from the serious application of quarantine measures directed against the advance of human trypanosomiasis and dependent for their efficiency upon cervical gland palpation.

The measures recommended are briefly : (1) the establishment of medical posts of inspection along the trade routes leading from infected to uninfected districts; and (2) the removal of infected persons from posts in uninfected districts to places already infected. If success is to be obtained the application of these measures must be thorough. The details of the way in which they are to be made effective cannot be considered here. They must be left to those who are to administer them. It may be suggested, however, that in most instances it will be impossible for the existing medical officers to enforce such measures in addition to performing their ordinary duties. The situation is quite serious enough to require the whole attention of special medical officers aided by competent staffs.

As an example of the applicability of the proposed measures consider the case of Nyassaland. It is certain (see Map 1) that the natives of the southern as well as of the northern shores of Lake Tanganyika will shortly be very heavily infected with trypanosomiasis. Labourers are engaged from the neighbourhood of Tanganyika to work in Nyassaland. There is constant communication between these two districts, since one of the most important caravan routes to Central Africa runs between Lake Nyassa and Lake Tanganyika. In my opinion, therefore, it is only a question of months before imported cases of the disease will be reported from Nyassaland. It is evident that the communication between these two areas should be stringently controlled. Posts of inspection should be established to prevent infected porters, in caravans, or labourers from entering British territory. Every employer of labour must be made to understand the danger of enlarged neck glands and should be instructed to send negroes possessing them to the nearest post of inspection. Each person residing or travelling in uninfected areas must be made personally responsible for the presence of persons with enlarged glands in his following. It is believed that the difficulties of applying these measures will not be as great as might be anticipated. Natives will soon learn and appreciate the danger of enlarged glands; they have long recognised their significance in Sierra Leone, Uganda, and in parts of the Congo Free State. It will admittedly be impossible altogether to control the movements of individuals, but it is not from single persons, as a rule travelling only a few miles, that danger is to be apprehended. It is the orgarised transport of groups of negroes which is dangerous.

It is concluded that: 1 . The enormous spread and great increase of sleeping sickness in the Congo basin have been due in great measure to the increase in travel following the opening up of the country. 2. Cases of trypanosomiasis, though apparently healthy, may be detected by their enlarged glands. 3. We may expect to check the advance of the disease by the serious application of quarantine palpation.

Addendum.-Since this paper was written apparently trustworthy reports have appeared in the daily press asserting that sleeping sickness has already appeared among the natives inhabiting the western shores of Lake Moero. The disease is spreading rapidly towards British Central Africa. The need for action is immediate.

Runcorn.

\section{A NOTE ON THE ACTION OF THE SERUM OF VARIOUS MAMMALS ON THE BACILLUS PESTIS.}

BY GEORGE LAMB, M.D. GLASG., CAPTAIN, Y.M.S. ;

$\triangle N D$

W. H. O. FORSTER, M.B., C.M. EdiN., D.P.H. Cantab., CAPTAIN, I.M.S.

THE etiology of plague offers the bacteriologist many interesting problems for solution. Of these problems one of great general interest is the immunity enjoyed by some members of the order of mammalia under natural and artificial conditions of infection.

The Indian Plague Commission found that rats, mice, squirrels (Indian variety), and monkeys were all susceptible to the disease under natural conditions of infection and that there was proof of epidemics having occurred in the case of all these animals. Of these animals it was stated that the grey monkey (Semnopithecus entellus) was more susceptible than the brown monkey (Macacus radiatus). The cat was also found to be susceptible under natural conditions of infection, the disease running a chronic course and taking the form of buboes in the neck accompanied by wasting. Dogs, jackals, and birds apparently did not contract the disease in nature.

The finding of the German Commission after laboratory investigation was as follows :-Rats and guinea-pigs are very susceptible ; mice are a little less susceptible ; monkeys are nearly as susceptible as rats, the grey monkey being the most susceptible; cats are less susceptible. Dogs, pigs, oxen, sheep, and goats sicken after large doses but soon recover. On the whole they are little susceptible. Birds, snakes, lizards, and frogs are insusceptible.

Simpson and Hunter ${ }^{1}$ claim to have succeeded in producing the disease by feeding upon material containing bacillus pestis several species of domestic animals and birds (pigs, cattle, hens, turkeys, ducks, geese, and pigeons). Since the publication of Simpson's results Pitchford in Natal and Bannerman in Bombay have been totally unable to reproduce them. Captain G. Liston, I.M.S., ${ }^{2}$ has recently shown that the guinea-pig when placed under natural conditions of infection readily contracts the disease.

So far as we are aware, the only mammals in India which have been definitely proved to be capable of contracting the disease under natural conditions of infection are rats, mice, squirrels, guinea.pigs, cats, and monkeys. These facts, we think, point to the desirability of a careful investigation of the action of the body fluids and formed elements of different animals of the order of mammalia on bacillus pestis. Up to date but little work has been done on unimmunised animals, and until we are acquainted with the action of normal serum, \&c., on bacillus pestis the immunity of the larger mammals will remain unexplained.

Wright and Windsor, ${ }^{3}$ using methods of high precision, showed that normal human serum is devoid of bactericidal action on the bacillus pestis. The methods of these observers were as follows:-

1. Equal volumes of normal human serum and a graded series of dilutions of a broth culture of bacillus pestis were kept in contact for from 18 to 24 hours at $37^{\circ} \mathrm{C}$. At the same time a parallel series was prepared consisting of equal volumes of sterile broth and the dilutions of the plague

1 Simpson: A Treatise on Plague, p. 116, University Press, Cambridge.

2 Indian Medical Gazette, February, 1905

3 Journal of Hygiene, Oct. 1st, 1902 